\title{
Emotional Intelligence: Pathway to Improved Leadership Capacities in Nigeria
}

\author{
Bassey Benjamin Esu \\ Department of Marketing, University of Calabar, Calabar, Nigeria \\ Email: esubenjamin@yahoo.com
}

Accepted: November 17, 2012 Published: December 27, 2012

Doi:10.5296/jsr.v3i2.3004 URL: http://dx.doi.org/10.5296/jsr.v3i2.3004

\begin{abstract}
The importance of emotional intelligence to employees' career development and success has been stressed in business papers. The concept is a widely used managerial tool that cuts across all industries in advanced societies. The extent of its appreciation and utilization in Nigeria is still in doubt in terms of academic research and individual and organizational applications. The orchestrated benefits of emotional intelligence are crucial to employee's career and are within the domains of employee development and performance which are relevant for nation building. There is also a dearth of knowledge as to the effect of emotional intelligence on leadership type and impact in Nigeria. This paper seeks to investigate relevant literature on the subject with reference to Nigeria so as to ascertain the level of applicability of the concept and make appropriate recommendations that will help leadership growth through the adoption of emotional intelligence principles in leadership training and placement. The paper also discussed the evolution of emotional intelligence, the taxonomy of emotional intelligence, empirical evidence of the effect of emotional intelligence on performance and measurement of emotional intelligence.
\end{abstract}

Keywords: Emotion, emotional intelligence, intelligent quotient, leadership, motivation, emotional competencies.

\section{Introduction}

The drive by practitioners and researchers to identify success factors in the human element in the work place has been unrelenting. This has lead to the emergence of the phenomenon, 'emotional intelligence (EI). Emotional intelligence has become a vital means of how today's leaders meet the significant challenges facing them.

The importance of emotional intelligence to employer's career development and success has been stressed in business papers. However, most organizations in Nigeria are yet to appropriate the orchestrated benefits of the phenomenon. This may not be unconnected with 
the political and social development of the country. Since business organizations operate in a global market, it is reasonable that, the concept of emotional intelligence be made an important leadership tool to enhance the global competitiveness of both public and private organizations in Nigeria. The skills are crucial to employee's career and are within the domains of employee development and performance. This paper will investigate the extent of appreciation and applicability of the concept in the Nigeria business environment through search of relevant literature. It discusses the evolution of emotional intelligence, the taxonomy of emotional intelligence, empirical evidence of the effect of emotional intelligence on performance, measurement of emotional intelligence and relevance in leadership.

\section{Evolution and Meaning of Emotional Intelligence}

The concept, emotional intelligence is traced to the early work of Thordike in 1920 on 'intelligent quotient' (IQ) and Gardner in 1980 on 'multiple intelligence' (include: linguistic, logical - mathematical, bodily - kinesthetic, spatial, musical, interpersonal, and intrapersonal) (Opengart, 2005). A review of related literature on this subject revealed that there is a taxonomical difficulty encountered when one attempts to define what EI is. The concept is defined differently by different authors or researchers. The definitions are captured from three major models that have dominated much of the writings to date (Clarke, 2006). The three models are:

- $\quad$ Ability Model: (Salovey \& Mayer, 1990; Mayer, Salovey, Caruso \& Sitorenios, 2002 and 2005).

- $\quad$ Mixed Ability Models (Bar-on, 1997; Dulewicz \& Higgs, 2000).

- $\quad$ Personality Models (Cherniss \& Goleman, 2001).

The ability model was developed be Salovey and Mayer (1990). The model refers to EI as ones emotional abilities. Under this model, emotional abilities is define as "the ability to monitor ones' own and others' emotions, to discriminate among them, and to use the information to guide ones' thinking and actions". The features of emotional abilities include:

a) The ability to perceive emotion,

b) The ability to integrate emotion to facilitate thought

c) The ability to understand emotions, and

d) The ability to manage emotions

The protagonist of mixed ability model is Bar-on (1997). In the mixed ability model, the constructs or domain are emotional and social competent behaviours and qualities. It comprises of personality and emotional abilities necessary to manage emotions. Under the mixed model, EI is defined as "an array of non-cognitive capabilities, competencies and skills that influence one's ability to succeed in coping with environmental demands and pressures".

The domain is made of five dimensions; intrapersonal skill, interpersonal skill, adaptability 
skill, stress management skills and general mood.

The personality model is the most popular and was advocated by Goleman and his colleagues (Cherniss \& Goleman, 2001; Goleman, 1998). The domain here is emotional competencies. In this model EI is define as "abilities, such as being able to motivate oneself and persist in the face of frustrations; to control impulse and delay gratification; to regulate one's moods and keep distress from swamping the ability to think; to empathize and to hope" (Goleman,1998). The domain has five dimensions; self awareness, self regulation, self motivation, social awareness, (empathy), and social skills (adeptness in relationships). It is believed that emotional competencies are pivotal to learning job - related skills and can result in outstanding performance at work. Our emotional intelligence determines our potential for having the practical skills that are based on the five elements.

Some beliefs about EI adapted from the work of Merkowitz and Ernest (2006) have come to be regarded as the tenets of EI. These include the following:

- Emotional intelligence is the most important factor in achieving success.

- High levels of achievement, success and happiness are self - defined and directed.

- The effect of negative and unchecked emotional stress, ineffective and poor relationships, and personal stagnation are financially costly.

- A personal and emotional accountability system is essential for positive human development.

- Honest self assessment is requisite to positive and intentional personal change.

- People develop and change themselves.

- Learners learn best and teachers teach best in environment that are physically and emotionally safe.

- Personal meaning is more relevant and powerful than external meaning

- Education and learning require the perspective of balance between academic achievement and becoming emotionally intelligent.

- Healthy and effective relationship, personal leadership, self-management, intrapersonal growth and development, and recognition of potential problems are essential elements for creating positive and healthy learning stimuli.

\section{Measurement of Emotional Intelligence}

The barometer for measuring one's level of emotional intelligence is a function of the model and domain emphasized by the analyst. I shall therefore discuss the indicators in each test measurement (Law et al, 2004).

Ability model: The emotional abilities are measured using Mayer - Salovey - Caruso Emotional Intelligence Test (MSCEIT, EQ-i). EQ-i stands for emotional quotient inventory. The individual is usually measure on four components: perceiving emotions; using emotions to facilitate thinking; understanding emotions; and managing emotions. 
Mixed ability model: The Bar-on Emotional Quotient Inventory is used to test for emotional intelligence in the case of mixed ability model. The instrument measures 5 components and 15 subcomponents. These include:

- Intrapersonal: Assertiveness, self regard, self actualization, independence, and self awareness

- Interpersonal: Interpersonal relationships, social responsibility, and empathy

- $\quad$ Adaptability: Problem solving and flexibility

- $\quad$ Stress management: Impulse control, and stress control

- $\quad$ General mood: Happiness and optimism

Personality model: The Emotional Competence Inventory (ECI), a multi-rate instrument is used to measure a series of behavioural indicators. It is a self reporting test. It measures the following attributes: social awareness, self regulation, self motivation, social awareness and social skills. On comparative basis, the MSCEIT is said to have far more accurate measure of distinct emotional abilities than the self - report measures associated with the other two approaches.

\section{Empirical Evidences of Emotional Intelligence On Performance In The Workplace}

The following evidences show the efficacy of the implementation of the concept of emotional intelligence in the work place.

According to Goleman, (2001), evidence suggests that emotionally intelligent leadership results in improved business performance. This assertion is strongly supported by the report of the study on leadership skills and emotional intelligence by the Centre for Creative Leadership USA. The study reveals that, higher levels of emotional intelligence are associated with better performance in the following areas:

- Participative management

- Putting people at ease

- Self - awareness

- Balance between personal life and work

- Straight forwardness and composure

- Building and mending relationships

- Doing what it takes

- Decisiveness

- Confronting problem employees

- Change Management

In another research, it was found that emotions are essentially contagious and thus a leader's attitude and energy can "infect" a workplace either for better or for worse. This brings in the concept of resonance (the ability of leaders to perceive and influence the flow of emotions 
between themselves and others they work with). The understanding of resonance effect of emotional intelligence on leadership led to the identification of six typologies of leadership styles (visionary, coaching, affiliative, democratic, pacesetting, and commanding). This was based on the outcome of a research on 3,871 executives conducted by Goleman, Boyatzis \& Mckee (2002). The six leadership styles are;

Style 1: Visionary: This describes leadership that inspires people by focusing on long - term goals. He/she is a good listen and can explain his/her overall goals for the organization in a way that wins the support of team members.

Style 2: Coaching: This describes leadership that helps people assume responsibility that leads to the success in the organization. The leader helps employees to work out for themselves how they can find additional information and resources. He effectively delegates authority within his /her area of responsibility.

Style 3: Affiliative: It describes the type of leadership that creates a warm, people- focused working atmosphere. An affiliative leader listens and accommodates the employee's emotional needs in the workplace.

Style 4: Democratic: This describes leadership that obtains inputs and commitments from every one in the group.

Style 5: Pacesetting: It describes leadership that sets ambitious goals and continually monitors progress toward these goals.

Style 6: Commanding: It describes leadership that issues instructions without asking for input about what is to be done or how: "do it because I say so".

A mixed of resonance and emotional intelligence leads to two typologies of leadership; resonance builders and dissonant. Styles $1-4$ are described as "resonance builders". Styles 5 and 6 are in contrast to the concept of emotional intelligence (described as "dissonant"). This is because the leaders are lacking in emotional intelligence.

\section{Studies On Emotional Intelligence In Nigeria}

There is a handful of literature on emotional intelligence appreciation and utilization in Nigeria ( Ofole and Falaye, 2011; Ofole, 2012). In this section, I shall look at some of the outstanding studies undertaken by academics in Nigeria in the area of emotional intelligence. Tella (2011) examines predictors of web search effectiveness among Library Information Sciences Undergraduates at University of Illorin. The study shows that there is no significant difference in occupational stress between secondary school teachers with low emotional intelligence and those with high emotional intelligence; no significant difference in the occupational stress between male secondary school teachers with low and those with high emotional intelligence; no significant difference in the occupational stress between female secondary school teachers with low and those with high emotional intelligence; no significant difference in the occupational stress between male and female secondary school teachers. In another study, Adeyemi and Ogunyemi (2005) examine the interactive and relative effect of emotional intelligence and self efficacy on occupational stress of university academic staff. The study found that emotional intelligence significantly contributes to the prediction of 
occupational stress of the participants. Nwokah and Ahiazu (2009) investigated the effect of emotional intelligence on marketing effectiveness. He observed a strong association between emotional intelligence and marketing effectiveness of corporate organizations in Nigeria; that emotional intelligence leads to marketing effectiveness in corporate organizations in Nigeria.

Akintayo (2010) investigated the effect of emotional intelligence and work-family role conflict in work organizations in Nigeria. The study revealed the following results: there was a significant combine contribution of emotional intelligence and work family role conflict to managerial effectiveness; that emotional intelligence significantly predicts managerial effectiveness of the managers; there is no significant contribution of work family role conflict to managerial effectiveness: that role conflict experienced by the managers resulting work family role interface has deleterious effect on the performance effectiveness. The study suggested that emotional intelligence should be considered in employee selection and placement process for managerial effectiveness to be guaranteed. Secondly, that those managers with high emotional intelligence should be posted to highly challenging managerial positions and vice versa.

Oyesoji (2008) carried out assessment of the relationship between emotional intelligence and performance of the Nigeria Police. One important outcome of the study is that personnel of the Nigeria Police do not have sufficient emotional intelligence. Secondly, demographic variables such as age, gender, work experience, marital status of men of the Nigeria Police do not lead to differences in their work performance. Ebitu, Mbum and Okon (2012) investigated the role of emotional intelligence on marketing segmentation and targeting in the four regions of Nigeria. The study revealed that market segment selection was influenced by emotional intelligence of marketers in designated centres (Abuja, Kano, Lagos and Port Harcourt); that there is a significant relationship between emotional intelligence and market targeting even though respondents had little or no knowledge of what emotional intelligence and utilization of its skills can do in scooping target or concentrated audience; that most marketers are unaware and have not leverage on the competence, skills and knowledge of emotional intelligence to select segments, target and position in the hearts, minds, and strategically or conspicuously site where customers must necessarily locate them, The study advocates that marketers should study, develop, and acquire some competencies to encourage, craft and sustain own emotions, others emotions and group emotions and apply it when selecting market segments .

Animasahun (2008) did an estimate of emotional intelligence, spiritual intelligence, and self efficacy and creativity skills on conflict resolution behaviour among the National Union of Road Transport Workers (NURTW) in the South Western Nigeria. The study found that there was significant relationship between emotional intelligence and conflict resolution behaviour of NURTW. The study also suggested that NURTW nationwide must be subjected to training in emotional intelligence and creativity skills as well as making arrangement for religious leaders to have consistent interactive sessions with the union. 
Ofole and Falaye (2011) measure the impact of emotional intelligence as modifying HIV risk perception on Road Safety personnel in Imo State Nigeria. The study revealed that significant difference on the HIV risk perception of treated group comparison with the counterpart in the control and that gender is not a factor in the perception of personnel ( risk irrespective of gender). Ofole (2012) in another study on the effectiveness of emotional intelligence therapy on attitude towards HIV counseling and testing on Road Safety personnel in Imo state in Nigeria found that there is a significant difference in HIV counseling and testing (HCT) attitude mean of tested group compare with the control group. That there is no significant difference in HCT attitude of males and females exposed to treatment.

\section{Relevance Of Emotional Intelligence To Leadership In Nigeria}

The author believes that the quality of leadership in Nigeria could improve, if the principles of emotional intelligence are introduced as management tool in the public and private sector of the Nigeria economy. This can be witness in the following areas:

i. Training in emotional intelligence will produce intelligent Nigerian leaders (Goleman, 2001).

ii. It will produce high need achievers who will drive the Nigeria to new frontiers.

iii. Training in emotional intelligence will produce Nigerian leaders who will lead by example (Goleman 2001).

iv. That emotional intelligence of Nigerians is not dependent on gender, age, or work status, but on willingness to inculcate the principles.

v. That Nigeria professional can improve their performance in their organizations through emotional intelligence. (Nwokah and Ahiauza, 2009; Ebitu, Mbum and Okon, 2012)

vi. That perception of Nigerians can be shaped and made result oriented through emotional intelligence (Adeyemi, 2005).

vii. That the security system and machinery of the country will meet citizen expectation if security personnel are trained on emotional intelligence in Nigeria (Oyesoji, 2008).

\section{Conclusion}

Emotional Intelligence is a relatively new concept in the management parlance in Nigeria. It is still more of an academic buzzword. There are not much empirical works on the subject in this area. This paper has explored some of the popular literature on the subject. The authors believe that the quality of leadership in Nigeria could improve, if the principles of emotional intelligence are introduced as a management tool in the public and private sector of the Nigeria economy. The paper concludes that the relevance of emotional intelligence cannot be over emphasized. Going by the current understanding of emotional intelligence and its benefits, one could easily suspect that the low citizenry morale, civic unrest, corruption and low productivity index experienced in the country in the past three decades is not 
unconnected with the absence of the application of emotional intelligence by managers and employers.

\section{References}

Adeyemi, D. A. (2005). Parental involvement interest in school and school environment as predictor of academic self efficacy among fresh secondary school in Oyo State Nigeria. Electronic Journal of Research in Educational Psychology, 5 (1): 165- 180.

Akintayo, D. I. (2010). Managerial effectiveness: Impact of emotional intelligence and work family role conflict in work organizations in Nigeria. Eastern Afriaca Social Science Research Review, 23(1): 23-40.

Anmashun. R. A. (2008). Prediction estimate of emotional intelligence, spiritual intelligence, self efficacy and creativity skills on conflict resolution behaviour among the NURTW in the South Western Nigeria. Pakistan Journal Life social Science, 6(2) : 68-74.

Bar-on, R. (1997) Bar-on Emotional Quotient inventory (Eq-i): A test of emotional intelligence, Toronto, Canada: Multi-health system.

Center for Creative leadership ( 2003). Leadership \& Emotional Intelligence

Cheniss, C. \& Goleman, D. (2001). Training for emotional intelligence : A model, . In C. Cherniss \& D. Goleman (Eds). The emotional intelligent workplace, San Francisco Jossy - Bass.

Clarke, N. (2006). Emotional Intelligence Training: A case of cavert emptor, Human Resources Development Review, 5(4): 422 - 441.

Dulewicz, V. \& Higgs, M. I. (2000). Emotional Intelligence: A review and evaluation study. Journal of Managerial Psychology, 15(1) :95 - 111 .

Ebitu, E. T., Mbum, P. A \& Okon, A. E. (2912). An exploration of emotional intelligence and market segmentation targeting, and positioning in selected central Business Districts in Nigeria. Journal of Marketing Studies, 4(3): 173-180.

Gardner, H. (1993). Frames of Mind, New York: Basic Books.

Goleman, D. (1995), Working with emotional intelligence, New York: Bantam.

Goleman, D. (2001). An EI based theory of performance. In C. Cherniss \& D. Goleman (Eds). The emotional intelligence workplace (pp. 27 - 45). San Francisco: Jossy Bass. 


\section{Macrothink}

Journal of Sociological Research

ISSN 1948-5468 2012, Vol. 3, No. 2

Goleman, D., Boyatzis, R. \& Mckee A. (2002). Primal leadership, Harvard Business School Press, http.www.business/listening.com/primal - leadership. retrieved on 10/03/11.

Mayer, J. D., Salovey, P. Caruso, D. R. \& Sitorenios, G. (2002). Mayer - Salovey Caruso Emotional Intelligence Test (MSCEIT). Users Manual Toronto, Canada. Multi Health System.

Mayer, J. D., Salovey, P., Caruso, D. R. \& Sitorenios, G. (2005). Measuring Emotional Intelligence with MSCEITV2.0. Emotion, 3, 97 - 105.

Merkowitz, R. F. \& Earnest, G. W. (2000) Emotional Intelligence: A pathway to self understanding and improved leadership capabilities.

Nwokah, N.G. \& Ahiauzu, A. I. (2009). Emotional intelligence and marketing effectivessness. Journal of Marketing Practice: Applied Marketing Science, 27 (7): 864-881.

Ofole, N. M \& Falaye, A. (2011). Impact of emotional intelligence training on modifying HIV risk perception on Road Safety Personnel in Imo State, Nigeria. Ozean Journal of Social Sciences, 4(1): 11-17.

Ofole, N. M. (2012). Effectiveness of emotional intelligencetherapy on attitude towards HIV counseling and testing of Road Safety Personnel in Imo State, Nigeria. African Journal of Social Sciences, 2(1): 76-86.

Opengart, R. (2005), Emotional Intelligence and emotion work examining constructs from interdisciplinary framework, Human Resource Development Review, 4(1), 49 - 62

Oyesoji, A. A \& Oluwayemisi, T. T. (2008). Assessment of emotional intelligence among Nigeria Police. Journal of Social Sciences, 16(3): 221-226.

Salovey, P \& Mayer, J. D. (1990). Emotional Intelligence Imagination, Cognition and personality, $9: 185-211$.

Tella, A. (2011). Emotional intelligence of LIS University of Illorin. Predictors of undergraduate s' students web search effectiveness . International Journal of Information Studies, 3(3): 96-105. 